\title{
Evaluation of the Effect of Pentoxifylline on Cisplatin-Induced Testicular Toxicity in Rats
}

\author{
Ali Reza Fallahzadeh', Zohreh Rezaei ${ }^{2}$, Hamid Reza Rahimi ${ }^{3,4}$, Mehrazd Jafari Barmak', Hossein Sadeghi ${ }^{1}$, \\ Sadrollah Mehrabi ${ }^{1}$, Seyed Mohammadreza Rabani ${ }^{1}$, Iraj Ragerdi Kashani ${ }^{5}$, Vahid Barati ${ }^{2}$ and Reza Mahmoudi ${ }^{1}$ \\ ${ }^{1}$ Cellular and Molecular Research Center, Yasuj University of Medical Sciences, Yasuj, Iran \\ ${ }^{2}$ Student Research Committee, Yasuj University of Medical Sciences, Yasuj, Iran \\ ${ }^{3}$ Pharmaceutics Research Center, Institute of Neuropharmacology, Faculty of Pharmacy, \\ Kerman University of Medical Sciences, Kerman, Iran \\ ${ }^{4}$ Department of Toxicology and Pharmacology, Faculty of Pharmacy, Kerman University of Medical Sciences, Kerman, Iran \\ ${ }^{5}$ Department of Anatomical Sciences, School of Medicine, Tehran University of Medical Sciences, Tehran, Iran
}

\begin{abstract}
Chemotherapy is associated with male infertility. Cisplatin (cis-diamminedichloro-platinum (II) (CDDP) as a chemotherapy medication used to treat a number of cancers has been reported to most likely induce testicular toxicity. Administration of antioxidants, such as pentoxifylline (PTX) may reduce some Adverse Drug Reactions (ADRs) of CDDP. Therefore, this study investigated the potentially protective effects of PTX on CDDP-induced testicular toxicity in adult male rats. For this purpose, 42 male rats were randomly divided into 7 groups. The rats were orally pretreated with PTX at the 3 doses of 75,150 , and $300 \mathrm{mg} / \mathrm{kg}$ once a day for 14 successive days. On the $14^{\text {th }}$ day of the study, they were intraperitoneally (IP) administered with a single dose of CDDP $(7 \mathrm{mg} / \mathrm{kg})$. Finally, the sperm/testis parameters, serum levels of reproductive hormones, including testosterone, Luteinizing Hormone (LH), and Follicle Stimulating Hormone (FSH) as the pivotal endocrine factors controlling testicular functions, and histopathological changes of testis tissue were examined. Pretreatment with the two doses of 75 and $150 \mathrm{mg} / \mathrm{kg}$ PTX indicated significant increases in the sperm count and motility induced by CDDP administration. The right and significantly left testis weights were decreased following the treatment with $300 \mathrm{mg} / \mathrm{kg}$ of PTX plus CDDP. However, $75 \mathrm{mg} / \mathrm{kg}$ of PTX plus CDDP showed the best near-to-normal histopathological features. The results demonstrated that PTX alone enhanced some parameters, such as the sperm count, while reducing other parameters, including sperm fast motility and germ layer thickness. Furthermore, despite testosterone or LH levels, the mean serum FSH level was significantly augmented by the doses of 75 and $150 \mathrm{mg} /$ $\mathrm{kg}$. It was concluded that PTX administration cannot reduce CDDP-induced testicular toxicity even at high doses (e.g., $300 \mathrm{mg} / \mathrm{kg}$ ), while it seemed to partially intensify CDDP toxicity effects at a dose of $75 \mathrm{mg} / \mathrm{kg}$. Thus, further research is required in this regard.
\end{abstract}

Key words: Chemotherapy, Testicular toxicity, Antioxidant, Histopathological feature, Sperm motility

Correspondence to: Reza Mahmoudi, Cellular and Molecular Research Center, Yasuj University of Medical Sciences, Yasuj, Iran E-mail: rmahmoudi40@yahoo.com

Hamid Reza Rahimi, Department of Toxicology and Pharmacology, Faculty of Pharmacy and Pharmaceutics of Neuropharmacology Institute, Kerman University of Medical Sciences, Kerman, Iran; P. O. Box: 7616911319

E-mail: hamidrrt@yahoo.com; h_rahimi@kmu.ac.ir
This is an Open-Access article distributed under the terms of the Creative Commons Attribution Non-Commercial License (http:// creativecommons.org/licenses/by-nc/3.0) which permits unrestricted non-commercial use, distribution, and reproduction in any medium, provided the original work is properly cited. 


\section{INTRODUCTION}

Infertility and its related problems are a major issue in today's marital affairs (1). According to statistics, 35\% of infertility cases are related to men, while $25 \%$ relate to both partners (2). The inability to produce a sufficient number of healthy and active sperms is the most common cause of male infertility $(3,4)$. Here, it should be pointed out that cancer chemotherapy drugs, antibiotics, toxins, pesticides, radiation, stress, air pollution, inadequate levels of vitamins, and administration of glucocorticoids are the factors contributing to poor sperm production and consequent male infertility (5-8). Chemotherapy and radiation therapy are associated with changes in the male genital tract. In chemotherapy, drugs with alkalizing properties have the highest dose-dependent ADRs on testicles (6).

CDDP is a chemotherapy medication that forms DNA adducts resembling bifunctional alkylating agents. CDDP can be used to treat various tumors, including ovarian, testicular, bladder, head and neck, lung, and cervical and endometrial tumors, as well as sarcoma and lymphoma $(9,10)$. However, due to its harmful effects on the kidneys, peripheral nerves, inner ear, and testicles, the use of this drug has been limited (11-14). The main reason for the restriction in its therapeutic efficacy is its toxic effects on the reproductive system causing severe testicular damage, which can be identified with the death of zoogenic cells in the process of spermatogenesis and sperm DNA damage $(15,16)$.

PTX is a derivative of methyl xanthine that can be applied for the treatments of peripheral vascular disease, cerebrovascular disease, or conditions causing topical disturbance on microcirculation due to its effects on blood flow and glutathione (GSH) (17). This compound can enhance chemotactic responses of neutrophils, while it may hinder the phagocyte and superoxide productions of neutrophils and monocytes $(18,19)$. PTX is a hemorheologic active compound, which is used for the treatment of intermittent claudication in the foot and other vascular disorders and can inhibit phosphodiesterase (PDE), which leads to augmented levels of intracellular cAMP (17,20-22). Due to playing a role in improving sperm function, PTX has attracted much attention. cAMP plays a role in the control of motile spermatozoa. Nevertheless, its numerous protective mechanisms are less clear $(20,21)$.

PTX beneficial effects on sperm function and male infertility have been noted in several studies $(23,24)$. Yet, there are some controversies in its beneficial effects on sperm function and semen parameters $(25,26)$. Furthermore, research has shown that PTX has anti-inflammatory and antioxidant effects in addition to its useful effects on blood circulation (27). Thus, given the role of oxidants in the incidence of testicular toxicity induced by CDDP and PTX useful properties, it was decided to examine PTX protective effects on CDDP-induced testicular toxicity.

\section{MATERIALS AND METHODS}

Animals. A total of 42 male Wistar rats $(180 \sim 200 \mathrm{~g})$ housed under the standard condition, including $12 \mathrm{hr}$ of darkness, $12 \mathrm{hr}$ of light, and a temperature of $25 \pm 2^{\circ} \mathrm{C}$ with free access to adequate amount of food and water in order to comply with the required situation was employed. All the animal experiments were performed according to the ethical guidelines suggested by the animal ethics committee of Yasuj University of Medical Sciences (Yasuj, Iran).

Treatment. The animals were randomly divided into 7 groups and treated for a period of 14 consecutive days. The rats were weighed once prior to the study and once before being sacrificed. Group A served as the control, which was daily gavaged with Distilled Water (DW). Group B received DW orally once a day for 14 days, while being once injected with $7 \mathrm{mg} / \mathrm{kg}$ of CDDP intraperitoneally (IP) on the $14^{\text {th }}$ day of the study. Group C received $75 \mathrm{mg} / \mathrm{kg}$ of PTX orally once a day for 14 days, while being once injected with 7 $\mathrm{mg} / \mathrm{kg}$ of CDDP intraperitoneally (IP) on the $14^{\text {th }}$ day of the study. Group D received $150 \mathrm{mg} / \mathrm{kg}$ of PTX orally once a day for 14 days, while being once injected with $7 \mathrm{mg} / \mathrm{kg}$ of CDDP intraperitoneally (IP) on the $14^{\text {th }}$ day of the study. Group E received $300 \mathrm{mg} / \mathrm{kg}$ of PTX orally once a day for the period of 14 days, while being once injected with $7 \mathrm{mg} /$ $\mathrm{kg}$ of CDDP intraperitoneally (IP) on the $14^{\text {th }}$ day of the study. Group F received $150 \mathrm{mg} / \mathrm{kg}$ of PTX orally once a day for the 14-day period. Group $\mathrm{G}$ received $300 \mathrm{mg} / \mathrm{kg}$ of PTX orally once a day for 14 days.

Sperm quality evaluation. To examine the sperm quality, first, the tail of the epididymis was cut and kept in T6 medium. Then, it was divided into pieces and hence, the sperm was inserted into T6. Morphology, number (count), and movement (motility) of the sperms were examined in all the study groups $(28,29)$.

Hormone measurement. The rats in all the groups were weighed on the $1^{\text {st }}$ and $14^{\text {th }}$ days of the study. After the 14-day period, the weighed rats were anesthetized with ketamine $(40 \mathrm{mg} / \mathrm{kg}) / \mathrm{xylazine}(10 \mathrm{mg} / \mathrm{kg})$ and their abdomens were opened to take their blood samples from their hearts and examine their serum testosterone, $\mathrm{LH}$, and FSH levels.

Histopathological examination. All the animals were sacrificed and their testicular tissues were fixed by $10 \%$ neutral buffered formalin, embedded in paraffin, rehydrated, and cut into $5 \mu \mathrm{m}$-thick sections using a rotary microtome. The sections were stained with hematoxylin and eosin (H\&E), mounted in Canada balsam, and then evaluated with a light microscope to determine any histological changes. Furthermore, epididymis was used to assess sperm parameters. 
Statistical analysis. The Statistical Package for Social Sciences (SPSS 22, IBM, NY, USA) software was utilized for the statistical analysis. The variables in terms of homogeneity of variance and a normal distribution were examined. If they contained a normal distribution and equal variance, analysis of variance (ANOVA) would be used and otherwise, Kruskal-Wallis one-way test would be applied. To specify the different groups, Tukey test was employed. The significance tests of $p<0.05$ were considered.

\section{RESULTS}

Body weight changes. The mean body weights of the rats were significantly reduced after treatment with CDDP or CDDP combined with PTX at a dose of $300 \mathrm{mg} / \mathrm{kg}$. However, $75 \mathrm{mg} / \mathrm{kg}$ of PTX could inhibit the animal's weight decrease. Moreover, administration of PTX alone showed no significant changes in the body weight (Fig. 1). The animal weight reduction could indicate toxicity during the treatment.

\section{Changes in sperm parameters.}

- Sperm count: The data demonstrated that the number of sperms in the group treated with CDDP (218.66 \pm

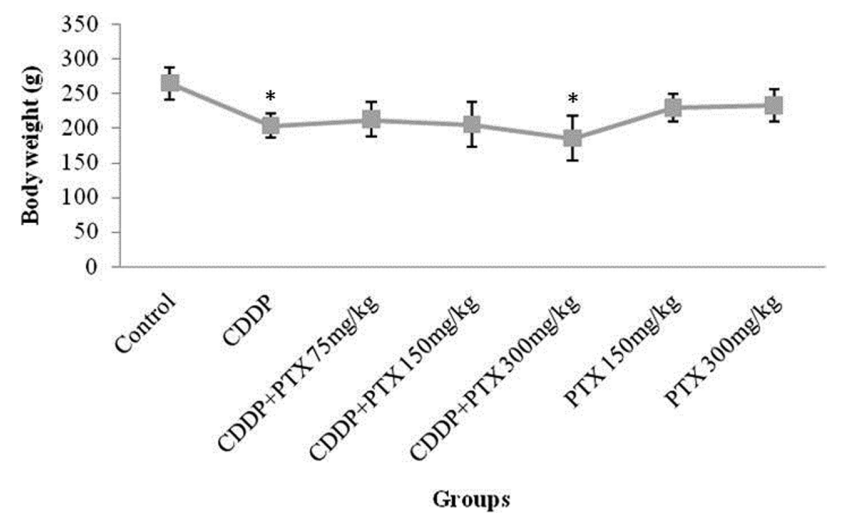

Fig. 1. The mean weight of the animals at the beginning and end of the ${ }^{*}$ indicated significant $(p<0.05)$ difference compared with control.
8.99) significantly reduced compared to that of the control group. The data also suggested that a concurrent administration of CDDP and PTX at a dose of $300 \mathrm{mg} / \mathrm{kg}$ with a mean of $90 \pm 30.35$ caused a significant reduction in the sperm count $(p \leq 0.01)$. On the other hand, administration of PTX alone at a dose of $150 \mathrm{mg} / \mathrm{kg}$ with a mean of $495.66 \pm 102.08$ led to a significant enhancement of the sperm counts of the treatment group compared to those of the control group. Furthermore, significant increase and decrease were observed in the group receiving PTX combined with CDDP at the doses of 75 and $300 \mathrm{mg} / \mathrm{kg}$ with the means of $444.50 \pm 19.96$ and $90 \pm 30.35$ compared to the group receiving CDDP alone, respectively. A significant difference was also observed with the coadministration of $150 \mathrm{mg} / \mathrm{kg}$ PTX and CDDP compared to the group receiving CDDP alone. Also, with the increasing dose of PTX up to $300 \mathrm{mg} / \mathrm{kg}$, a significant decline in the sperm count was witnessed as compared to the control group (Table 1).

- Sperm shape: The results demonstrated that the shapes of the sperm cells in the treated compared to the control group were not significantly different (Table 1).

- Sperm fast motility: Table 1 displays the mean and SD of the studied factors of the sperms isolated from the testicular tissues of the selected groups. Sperm fast motility in the control group was statistically significant $(p<0.001)$ compared to those of the other studied groups; however, the difference was not statistically significant in the groups receiving different doses of PTX combined with CDDP compared to the CDDP-administrated group.

- Sperm sluggish motility: Table 1 shows that the average percentage of the sluggish motilities of the sperms in the control group is $52.50 \pm 7.77$. In addition, statistically significant differences can be seen in the group receiving CDDP combined with the different PTX doses of 75, 150 , and $300 \mathrm{mg} / \mathrm{kg}$ with the averages of $14.25 \pm 1.10,1.75 \pm$ 0.62 , and $4 \pm 2.08$, respectively. The data obtained from 300 $\mathrm{mg} / \mathrm{kg}$ PTX were not significantly different compared with that of the control group. Moreover, a significant reduction was found in the groups receiving the different PTX doses of 75,150 , and $300 \mathrm{mg} / \mathrm{kg}$ combined with CDDP as compared with the CDDP group.

Table 1. Mean average (mean \pm SD) of rats' sperm parameters in treated groups

\begin{tabular}{|c|c|c|c|c|c|c|c|}
\hline Sperm parameters & Control & CDDP & $\begin{array}{c}\text { CDDP + PTX } \\
(75 \mathrm{mg} / \mathrm{kg})\end{array}$ & $\begin{array}{c}\text { CDDP + PTX } \\
(150 \mathrm{mg} / \mathrm{kg})\end{array}$ & $\begin{array}{c}\text { CDDP + PTX } \\
(300 \mathrm{mg} / \mathrm{kg})\end{array}$ & $\begin{array}{c}\text { PTX } \\
(150 \mathrm{mg} / \mathrm{kg})\end{array}$ & $\begin{array}{c}\text { PTX } \\
(300 \mathrm{mg} / \mathrm{kg})\end{array}$ \\
\hline Sperm count $\left(\times 10^{6} / \mathrm{mm}^{3}\right)$ & $340.75 \pm 22$ & $218.66 \pm 8.99^{*}$ & $444.50 \pm 19.96^{* \# \#}$ & $256.75 \pm 13.98^{* \#}$ & $90 \pm 30.35^{* * \# \#}$ & $495.66 \pm 102.08^{* \#}$ & $231 \pm 15.63^{*}$ \\
\hline \multicolumn{8}{|l|}{ Sperm morphology } \\
\hline Normal (\%) & $86 \pm 9.78$ & $93.33 \pm 1.96$ & $81.25 \pm 15.76$ & $81.25 \pm 15.41$ & $96.66 \pm 0.33$ & $97 \pm 0.01$ & $94.60 \pm 2.40$ \\
\hline Non-normal (\%) & $14 \pm 8.82$ & $6.66 \pm 1.89$ & $18.75 \pm 14.64$ & $18.77 \pm 15.43$ & $3.33 \pm 0.32$ & $3 \pm 0.02$ & $5.40 \pm 2.41$ \\
\hline \multicolumn{8}{|l|}{ Sperm motility } \\
\hline Fast (\%) & $33.75 \pm 7.78$ & $0^{* * *}$ & $0^{* * *}$ & $0^{* * *}$ & $1 \pm 1^{* * *}$ & $8.33 \pm 3.33^{* * \ldots \# \#}$ & $8.20 \pm 1.98^{* * \ldots \# \#}$ \\
\hline Slow $(\%)$ & $52.50 \pm 7.77$ & $26 \pm 10.03^{*}$ & $14.25 \pm 1.10^{* * \#}$ & $1.75 \pm 0.62^{* * * \ldots \#}$ & $4 \pm 2.08^{* * * \# \#}$ & $38.33 \pm 4.51^{* \#}$ & $55.60 \pm 6.58$ \\
\hline Non motility (\%) & $13.75 \pm 1.49$ & $74 \pm 12.71^{* *}$ & $68.75 \pm 17.92^{* *}$ & $98.25 \pm 4.77^{* * \#}$ & $95 \pm 3.65^{* * \#}$ & $53.33 \pm 5.02^{* * \#}$ & $36.20 \pm 7.47^{* \#}$ \\
\hline
\end{tabular}

${ }^{*} p<0.05,{ }^{* *} p<0.01,{ }^{* * *} p<0.001$ compared to control; ${ }^{*} p<0.05,{ }^{\# \#} p<0.01,{ }^{\# \# \#} p<0.001$ compared to CDDP-treated group. 
Non-motile sperms. The percentage of non-motile sperms in the control group was $13.75 \pm 1.49$ in comparison with the CDDP-receiving group and the group of CDDP combined with the different PTX doses of 75, 150, and 300 $\mathrm{mg} / \mathrm{kg}$ with the averages of $68.75 \pm 17.92,98.25 \pm 4.77$ and $95 \pm 3.65$, respectively, thus representing a statistically significant difference. Yet, the data of the group administrated with 150 and $300 \mathrm{mg} / \mathrm{kg}$ PTX did not reveal significant differences from that of the control group. Furthermore, no significant differences were observed in the groups receiving different doses of PTX plus CDDP as compared with the CDDP-receiving group (Table 1).

\section{Changes in testis parameters.}

- Left testis weight: Table 1 depicts a significant decrease in the left testicular weights of the groups receiving CDDP alone $(1.25 \pm 0.06 \mathrm{~g})$ and a combination of CDDP and $300 \mathrm{mg} / \mathrm{kg}$ PTX $(1.20 \pm 0.08 \mathrm{~g})$ compared with that of the control group $(1.53 \pm 0.02 \mathrm{~g} ; p=0.041)$. No statistically significant differences were observed in the left testis weights of the groups administered with different doses of PTX plus CDDP compared to the group receiving CDDP alone.

- Right testis weight: The right testicular weight in the CDDP-administered group was $1.24 \pm 0.05 \mathrm{~g}$ in comparison with that of the control group $(1.51 \pm 0.03 \mathrm{~g})$, thus revealing a statistically significant decrease $(p=0.037)$. However, the right testis weights of the groups receiving CDDP and $300 \mathrm{mg} / \mathrm{kg}$ PTX were reduced compared to that of the control group though this reduction was not statistically significant $(p=0.098)$. Besides, no significant differences were observed in the right testicular weights of the groups receiving different doses of PTX plus CDDP compared with that of the CDDP group (Table 2).

- Seminiferous tubule diameter: According to the data, the mean seminiferous tubule diameters of the treated groups compared with that of the control group indicated no statistically significant differences (Table 2). There was a decline in the mean seminiferous tubule diameters of the groups treated with different doses of PTX combined with CDDP with the means of $267.95 \pm 12.06,296.95 \pm 21.06$, and $275.09 \pm 14.16$, compared to the group treated with
CDDP alone $(330.08 \pm 28.80)$, respectively, but the reduction was not statistically significant.

- Zoogenic (germ) layer diameter: Table 2 exhibits that the diameters of the germ layers in all the groups were significantly decreased $(p<0.001)$ as compared to that of the control group. Additionally, a statistically significant reduction was found in the groups pretreated with a dose of 75 $\mathrm{mg} / \mathrm{kg}$ PTX plus CDDP with a mean of $57.88 \pm 3.64$ compared to that of the CDDP group (73.24 \pm 6.67$)$.

- Number of spermatogonial cells: The numbers of spermatogonia in the group receiving $300 \mathrm{mg} / \mathrm{kg}$ of PTX alone $(139.83 \pm 11.41)$ and the group treated with CDDP and $300 \mathrm{mg} / \mathrm{kg}$ PTX $(156.33 \pm 13.59)$ significantly increased compared to that of the control group $(84.5 \pm 4.23 ; p<0.01)$. Furthermore, a statistically significant enhancement was found in the group receiving CDDP and $300 \mathrm{mg} / \mathrm{kg}$ PTX compared to the group receiving CDDP alone. Yet, no simultaneous significant differences were observed in the other two groups administered with CDDP and PTX as compared to the group receiving CDDP alone (Table 2).

- Number of Leydig cells: The results were indicative of no significant differences between the studied and control groups based on the number of Leydig cells. In addition, a reduction was observed in the numbers of Leydig cells in the groups treated with different PTX doses of 75, 150, and $300 \mathrm{mg} / \mathrm{kg}$ in combination with CDDP with the means of $5.25 \pm 0.39,5.17 \pm 0.45$, and $5.01 \pm 0.36$ compared to that of the group treated with CDDP alone $(5.33 \pm 0.37)$, respectively, thus revealing a non-statistically significant variation.

- Number of sertoli cells: The numbers of sertoli cells in the studied groups compared with the control group represented no statistically significant differences (Table 1). The groups pretreated with 75 and $300 \mathrm{mg} / \mathrm{kg}$ PTX and CDDP at the two doses of $3.75 \pm 0.21$ and $4.33 \pm 0.28$ demonstrated a significant decline as compared to the CDDP group $(4.5 \pm 0.33)$, while no statistically significant augmentation was discovered in the group receiving $150 \mathrm{mg} / \mathrm{kg}$ PTX and CDDP $(5.24 \pm 0.31)$.

\section{Hormonal changes.}

- Serum testosterone level: The mean serum testosterone levels in the CDDP and concurrent CDDP- and

Table 2. Mean average (mean $\pm S D$ ) of rats' testes parameters in treated groups

\begin{tabular}{|c|c|c|c|c|c|c|c|}
\hline Testis parameters & Control & CDDP & $\begin{array}{c}\text { CDDP + PTX } \\
(75 \mathrm{mg} / \mathrm{Kg})\end{array}$ & $\begin{array}{c}\text { CDDP + PTX } \\
(150 \mathrm{mg} / \mathrm{kg})\end{array}$ & $\begin{array}{c}\text { CDDP + PTX } \\
(300 \mathrm{mg} / \mathrm{kg})\end{array}$ & $\begin{array}{c}\text { PTX } \\
(150 \mathrm{mg} / \mathrm{kg})\end{array}$ & $\begin{array}{c}\text { PTX } \\
(300 \mathrm{mg} / \mathrm{kg})\end{array}$ \\
\hline Left testis weight $(\mathrm{g})$ & $1.53 \pm 0.02$ & $1.25 \pm 0.06^{*}$ & $1.34 \pm 0.03$ & $1.35 \pm 0.04$ & $1.20 \pm 0.08^{* * \#}$ & $1.48 \pm 0.11$ & $1.49 \pm 0.02$ \\
\hline Right testis weight (g) & $1.51 \pm 0.03$ & $1.24 \pm 0.05^{*}$ & $1.37 \pm 0.04$ & $1.33 \pm 0.06$ & $1.23 \pm 0.09$ & $1.47 \pm 0.12$ & $1.49 \pm 0.01$ \\
\hline Seminiferous tubule diameter $(\mu \mathrm{m})$ & $268.63 \pm 13.49$ & $330.08 \pm 28.80$ & $267.95 \pm 12.06$ & $296.95 \pm 21.06$ & $275.09 \pm 14.16$ & $258.63 \pm 11.49$ & $251.94 \pm 10.07$ \\
\hline Germinal cell layer $(\mu \mathrm{m})$ & $262.69 \pm 14.22$ & $73.24 \pm 6.67^{* * *}$ & $57.88 \pm 3.64^{* * * \#}$ & $68.20 \pm 6.35^{* * *}$ & $82.83 \pm 6.33^{* * *}$ & $48.03 \pm 5.49^{* * * \#}$ & $54.6 \pm 4.02^{* * * \#}$ \\
\hline Spermatogonia cell number $\left(\mathrm{mm}^{2}\right)$ & $84.5 \pm 4.23$ & $115.25 \pm 3.24^{* *}$ & $108.58 \pm 6.78^{* *}$ & $116.33 \pm 3.85^{* *}$ & $156.33 \pm 13.59^{* * \#}$ & $140.01 \pm 8.49^{* * \#}$ & $139.83 \pm 11.41^{* * \#}$ \\
\hline Leydig cell $\left(\mathrm{mm}^{2}\right)$ & $5.33 \pm 0.61$ & $5.33 \pm 0.37$ & $5.25 \pm 0.39$ & $5.17 \pm 0.45$ & $5.01 \pm 0.36$ & $5.01 \pm 0.49$ & $4.5 \pm 0.33$ \\
\hline Sertoli cell $\left(\mathrm{mm}^{2}\right)$ & $4.02 \pm 0.36$ & $4.5 \pm 0.31$ & $3.75 \pm 0.21^{\#}$ & $5.24 \pm 0.31$ & $4.33 \pm 0.28^{\#}$ & $4.02 \pm 0.38$ & $4.02 \pm 0.27$ \\
\hline
\end{tabular}

${ }^{*} p<0.05,{ }^{* *} p<0.01,{ }^{* * *} p<0.001$ compared to control; ${ }^{\#} p<0.05$ compared to CDDP-treated group. 


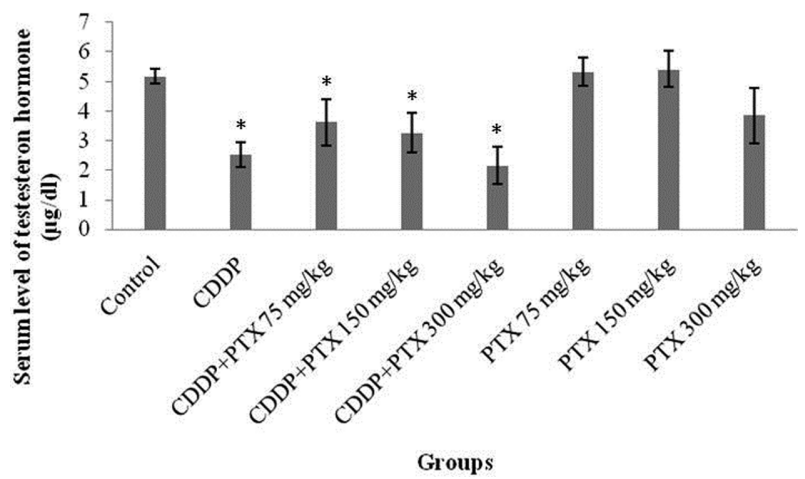

Fig. 2. Serum testosterone levels in study groups. * Indicated significant $(p<0.05)$ difference compared with control.

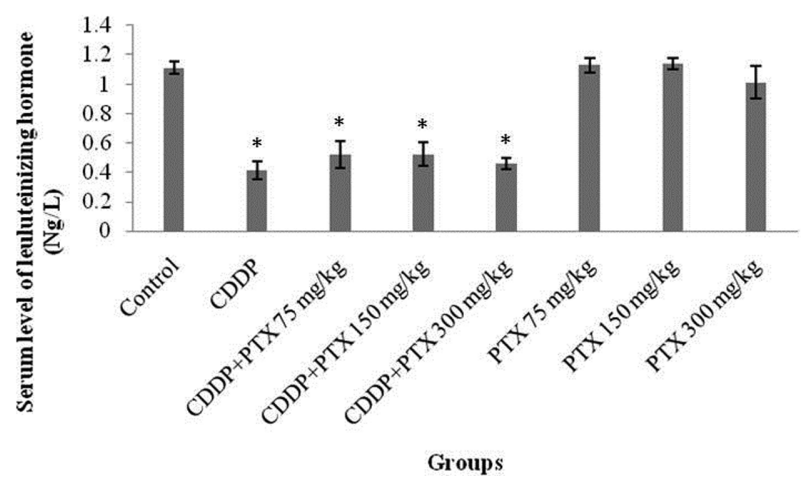

Fig. 3. The mean luteinizing hormone $(\mathrm{LH})$ in blood. * Indicated significant $(p<0.05)$ difference compared with control.

PTX-receiving groups at the different doses of $75,150,300$ $\mathrm{mg} / \mathrm{kg}$ were $2.52 \pm 0.42,3.62 \pm 0.71,3.25 \pm 0.67$, and $2.15 \pm$ $0.65 \mu \mathrm{g} / \mathrm{dL}$, respectively, thus representing a high signifi-

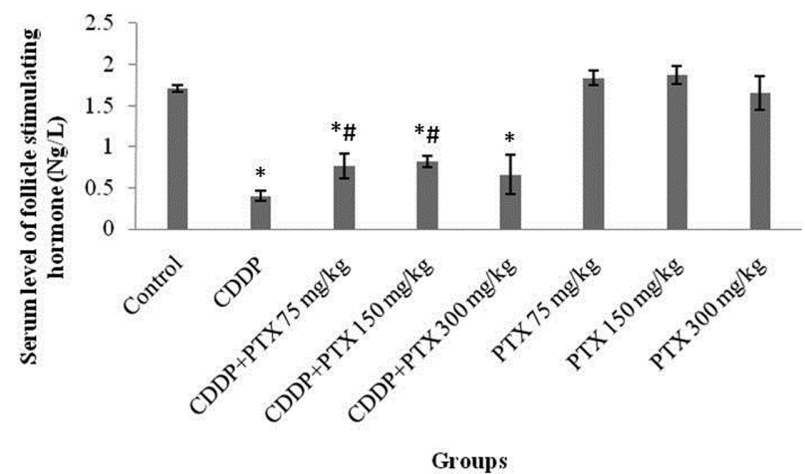

Fig. 4. The mean follicle stimulating hormone $(\mathrm{FSH})$ in blood. * Indicated significant $(p<0.05)$ difference compared with control; and \# indicated significant $(p<0.05)$ differences compared with CDDP group.

cant reduction in comparison with that of the control group $(5.17 \pm 0.26 \mu \mathrm{g} / \mathrm{dL} ; p<0.01)$. Despite that, the mean serum testosterone levels were slightly increased in the groups receiving 75 or $150 \mathrm{mg} / \mathrm{kg}$ of PTX plus CDDP compared with the CDDP group though this enhancement was not statistically significant. In any case, PTX at $300 \mathrm{mg} / \mathrm{kg}$ indicated the greatest reduction. Furthermore, testosterone levels in the PTX-administered group showed no significant difference from that of the control group (Fig. 2).

- Measurement of LH level in blood: No statistically significant alleviation was observed in the serum LH levels of the groups receiving different doses of PTX in combination with CDDP as compared to the CDDP group (Fig. 3).

- Measurement of FSH level in blood: Pretreatment with different doses of PTX $(75,150$, and $300 \mathrm{mg} / \mathrm{kg})$ combined with CDDP exhibited the means of $0.77 \pm 0.15,0.82 \pm$

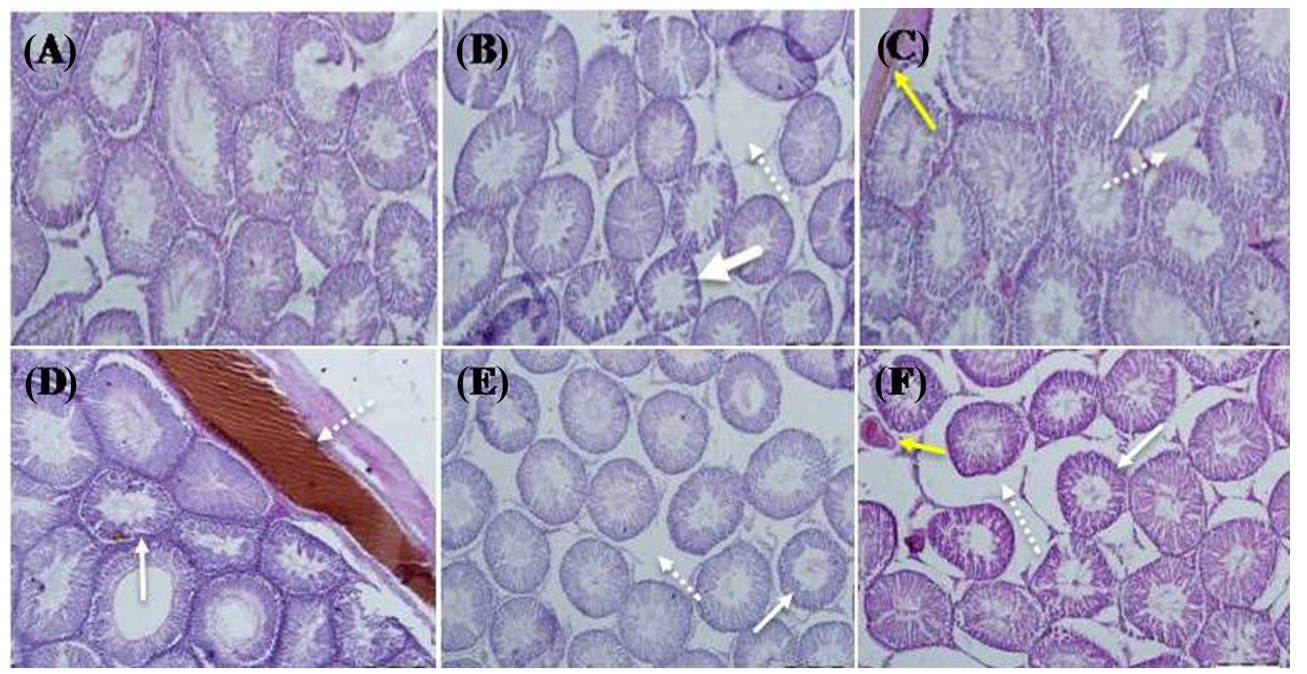

Fig. 5. Microscopic views of hematoxylin and eosin $(H \& E)$ - stained rat testes with $\times 40$ magnification. (A) Control group. (B) Rats treated with cisplatin (CDDP). (C) Rats treated by CDDP and PTX (75 mg/kg). (D) Rats treated by CDDP and PTX (150 mg/kg). (E) Rats treated by CDDP and PTX (300 mg/kg). (F) Rats treated with PTX (300 mg/kg). 
0.07 , and $0.66 \pm 0.24 \mathrm{Ng} / \mathrm{L}$, respectively, in comparison with $0.4 \pm 0.06 \mathrm{Ng} / \mathrm{L}$ for the CDDP group. A statistically significant elevation of FSH serum levels was observed in the groups receiving 75 and $150 \mathrm{mg} / \mathrm{kg}$ of PTX in combination with CDDP compared with that of the CDDP group. However, no significant changes were indicated at a dose of $300 \mathrm{mg} / \mathrm{kg}$ (Fig. 4).

- Histopathological analysis: The best near-to-normal histological features were revealed in the group of CDDP plus $75 \mathrm{mg} / \mathrm{kg}$ PTX by $\mathrm{H} \& \mathrm{E}$ as compared with those of the control group (Fig. 5C). In this Figure, the continuous arrows depict the diameters of seminiferous tubules and the non-continuous arrows display the normal thickness of the germinal layer. In addition, yellow arrows represent venous congestion (Fig. 5C). The control group portrayed normal seminiferous tubular and germinal epithelium diameters and spaces of seminiferous tubules (Fig. 5A). Decreased seminiferous tubular diameters (continuous arrows) and increased space between the seminiferous tubules (non-continuous arrows) were indicated in the testes of the rats treated with CDDP (Fig. 5B). Reduced seminiferous tubular diameter and thickness of germinal epithelium layer (continuous arrows) besides vascular congestion (non-continuous arrows) were observed in the testis sections of the rats treated with a dose of $150 \mathrm{mg} / \mathrm{kg}$ PTX and CDDP (Fig. 2D). Decreased seminiferous tubular diameters (continuous arrows) and increased spaces between the seminiferous tubules caused by the tissue edema (non-continuous arrows) were seen in the testis sections of the rats treated with a dose of $300 \mathrm{mg} / \mathrm{kg}$ PTX and CDDP as represented in Fig. 5E. Furthermore, Fig. 5F demonstrates a reduced seminiferous tubular diameter (continuous arrows) and tissue edema in the spaces between seminiferous tubules (non-continuous arrows) in addition to venous congestion (yellow arrows) in the testis sections of the rats treated with a dose of $300 \mathrm{mg} / \mathrm{kg}$ PTX.

\section{DISCUSSION}

This research was an experimental study conducted on PTX effects at the different doses of 75, 150, and $300 \mathrm{mg} /$ $\mathrm{kg}$ on CDDP-induced testicular toxicity in rats. According to the sperm/testis parameters, pretreatment with the two doses of 75 and $150 \mathrm{mg} / \mathrm{kg}$ PTX revealed significant increases in the sperm count and motility against CDDP administration. PTX alone enhanced some parameters, such as the sperm count, but reduced other parameters, including sperm fast motility and germ layer thickness. However, the right and significantly left testis weights were decreased following the treatment with $300 \mathrm{mg} / \mathrm{kg}$ of PTX plus CDDP. Histopathological results also indicated the best near-to-normal features of CDDP $+75 \mathrm{mg} / \mathrm{kg}$ PTX. Furthermore, the levels of reproductive hormones, such as FSH significantly rose at the doses of 75 and $150 \mathrm{mg} / \mathrm{kg}$ despite testosterone or $\mathrm{LH}$ levels as compared with CDDP level. The serum levels of testosterone, LH, and FS hormones make parts of the regulatory toxicity studies performed on the reproductive system. Therefore, PTX could not reduce CDDP-induced testicular toxicity even at high doses (e.g., $300 \mathrm{mg} / \mathrm{kg}$ ) although it seemed to partially intensify CDDP toxicity effects at a dose of $75 \mathrm{mg} / \mathrm{kg}$.

It has been reported that CDDP causes irregular seminiferous tubes, reduces seminiferous tubular epithelium and fibrosis around the vessels and melatonin, and helps to dramatically improve these changes by increasing the levels of GSH and glutathione peroxidase (GPX) activities, enhancing serum testosterone levels, and reducing malondialdehyde (MDA) levels (30). MDA results from the lipid peroxidation (LPO) of polyunsaturated fatty acids and serves as a marker for Oxidative Stress (OS). In the previous studies, the antioxidant effects of vitamin $\mathrm{C}$, diphenyldiamine (DPPD), and L-cysteine on the kidney and testicular toxicities of CDDP in rats were evaluated $(31,32)$. In those studies, CDDP was administered at the doses of 2 and $8 \mathrm{mg} / \mathrm{kg}$ for 2 weeks. The results of the CDDP-receiving groups showed that the levels of LPO, peroxidase, and superoxide anions significantly augmented. Furthermore, dramatic reductions in the activities of antioxidant enzymes, including superoxide dismutase (SOD), catalase (CAT), and glutathione transferase were observed. GSH levels were substantially lowered in the testes treated with CDDP compared with that of the control group. The CDDP-induced toxicity resulted from free radicals was biochemically reported to be generated in the tissues. However, the mechanism of CDDPinduced testicular damage is not well understood. Numerous studies have shown that exposure to CDDP can disturb redox balance, which is indicative of the oxidative type of the stress leading to the biochemical and physiological disorders $(33,34)$.

The sperms of mammals contain a unique lipid composition with high levels of polyunsaturated fatty acids, sphingomyelin, and plasmalogen. The unusual membrane structures of the sperms are responsible for their flexibilities and performance capabilities. Lipids in spermatozoa are the main precursors of peroxidation, which may stimulate severe abnormalities in the sperm functions $(35,36)$. In some experimental studies, Reactive Oxygen Species (ROS) is known to provide a mechanism for the pathogenesis of CDDP-induced testicular toxicity $(37,38)$. The concept of ROS encompasses oxygen ions, free radicals, and peroxidase, which can cause infertility via two main mechanisms. Firstly, the damage to the sperm membrane can reduce sperm motility and ability to fuse with the ovum. Secondly, the direct damage to the sperm DNA can cause some problems in the paternal genomic contribution to the embryo (39).

Due to the toxic effects of chemotherapy on fertility, researchers have used such techniques as cryopreservation of spermatozoa and Intra-Cytoplasmic Sperm Injection (ICSI) to retain the reproductive potentiality and increase 
the chances of a successful pregnancy. Nonetheless, there are restrictions on the use of these methods since these options are not practical for patients before maturation and additionally, semen freezing and thawing can reduce their sperm qualities (40). Therefore, alternative methods are required for protecting the epithelia of the seminiferous tubules and spermatogenesis against the testicular toxicity of anti-cancer agents. Although there are some concerns about the concurrent use of antioxidants and anti-cancer drugs due to the risk of reduced effectiveness of cytotoxic drugs, recent evidence suggests that a combination therapy with protective chemical agents can be helpful to overcome such toxic effects on reproduction $(32,41)$. In recent decades, several studies have shown that the administration of antioxidants from plant and food compounds may help decrease some of the side effects of CDDP without affecting its chemical properties or effects (42-44).

Some examples reported from various similar studies include grape seed extract, turmeric extract, caffeic acid in honey, melatonin, vitamin $\mathrm{C}$, vitamin $\mathrm{E}$, carotenoids, and many other materials with antioxidant mechanisms to either fully or partially reduce CDDP toxic effects on different body systems (30,45-50). Administrations of DPPD, L-cysteine, and vitamin $\mathrm{C}$ before CDDP injection have been shown to improve histological features and reduce the number of cells involved in apoptosis, which has been highest when using DPPD (31). Although the relevant studies have demonstrated the beneficial effects of antioxidants, such as PTX on the protection of the reproductive system from toxicity, there are some controversies for the use of PTX affecting the sperm function, semen parameters, or reproductive hormones (25-27). Furthermore, little is known about the protective mechanisms of PTX.

In conclusion, CDDP treatment can induce histopathological changes in testicular tissue through OS as evidenced by the enhanced free radicals, DNA fragmentation, and significant decreases in the enzymatic and non-enzymatic antioxidants. However, via pretreatment with antioxidants, PTX can partially protect CDDP-ADRs via different mechanisms, which mainly involve antioxidants and PTX antiinflammatory properties. In this research, CDDP was shown to induce testicular toxicity at high doses $(300 \mathrm{mg} / \mathrm{kg})$ and even a low dose of $75 \mathrm{mg} / \mathrm{kg}$, thus representing different cellular responses for diminishing its cytotoxic effects. Therefore, further research is required to explain these different behaviors.

Received October 28, 2016; Revised January 26, 2017; Accepted February 9, 2017

\section{REFERENCES}

1. Ebisch, I.M., Thomas, C.M., Peters, W.H., Braat, D.D. and Steegers-Theunissen, R.P. (2007) The importance of folate, zinc and antioxidants in the pathogenesis and prevention of subfertility. Hum. Reprod. Update, 13, 163-174.

2. Aryanpur, M., Tarahomi, M., Sharifi, H., Heydari, G., Hessami, Z., Akhoundi, M. and Masjedi. M.R. (2011) Comparison of spermatozoa quality in male smokers and nonsmokers of Iranian infertile couples. Int. J. Fertil. Steril., 5, 152-157.

3. Baker, M.A. and Aitken, R.J. (2004) The importance of redox regulated pathways in sperm cell biology. Mol. Cell. Endocrinol., 216, 47-54.

4. Amin, A. and Hamza, A.A. (2006) Effects of roselle and ginger on cisplatin-induced reproductive toxicity in rats. Asian J. Androl., 8, 607-612.

5. Martenies, S.E. and Perry, M.J. (2013) Environmental and occupational pesticide exposure and human sperm parameters: a systematic review. Toxicology, 307, 66-73.

6. Howell, S.J. and Shalet, S.M. (2005) Spermatogenesis after cancer treatment, damage and recovery. J. Natl. Cancer Inst. Monogr., (34), 12-17.

7. Mosher, W.D. and Pratt, W.F. (1991) Fecundity and infertility in the United States, incidence and trends. Fertil. Steril., 56, 192-193.

8. Schill, W.B. (1979) Recent progress in pharmacological therapy of male subfertility-a review. Andrologia, 11, 77-107.

9. Chirino, Y.I., Hernández-Pando, R. and Pedraza-Chaverrí, J. (2004) Peroxynitrite decomposition catalyst ameliorates renal damage and protein nitration in cisplatin-induced nephrotoxicity in rats. BMC Pharmacol., 4, 20.

10. Colpi, G.M., Contalbi, G.F., Nerva, F., Sagone, P. and Piediferro, G. (2004) Testicular function following chemo-radiotherapy. Eur. J. Obstet. Gynecol. Reprod. Biol., 113, S2-S6.

11. Atessahin, A., Yilmaz, S., Karahan, I., Ceribasi, A.O. and Karaoglu, A. (2005) Effects of lycopene against cisplatininduced nephrotoxicity and oxidative stress in rats. Toxicology, 212, 116-123.

12. Bhat, S.G., Nie, Z. and Ramkumar, V. (1999) Cisplatin up-regulates adenosine $\mathrm{A}(1)$ receptors in rat testes. Eur. J. Pharmacol., 382, 35-43.

13. Ozols, R.F., Deisseroth, A.B., Javadpour, N., Barlock, A., Messerschmidt, G.L. and Young, RC. (1983) Treatment of poor prognosis nonseminomatous testicular cancer with a "high-dose" platinum combination chemotherapy regimen. Cancer, 51, 1803-1807.

14. Stadnicki, S.W., Fleischman, R.W., Schaeppi, U. and Merriam, P. (1975) Cis-dichlorodiammineplatinum (II) (NSC119875), hearing loss and other toxic effects in rhesus monkeys. Cancer Chemother. Rep., 59, 467-480.

15. Fung, C. and Vaughn, D.J. (2011) Complications associated with chemotherapy in testicular cancer management. Nat. Rev. Urol., 8, 213-222.

16. Hooser, S.B., van Dijk-Knijnenburg, W.C., Waalkens-Berendsen, I.D., Smits-van Prooije, A.E., Snoeij, N.J., Baan, R.A. and Fichtinger-Schepman, A.M. (2000) Cisplatin-DNA adducts formation in rat spermatozoa and its effects on fetal development. Cancer Lett., 151, 71-80.

17. Ward, A. and Clissold, S.P. (1987) Pentoxifylline. A review of its pharmacodynamic and pharmacokinetic properties, and its therapeutic efficacy. Drugs, 34, 50-97.

18. Noyan, T., Onem, O., Ramazan Sekeroğlu, M., Köseoğlu, B., Dülger, H., Bayram, I., Yalçinkaya, A.S. and Bakan, V. (2003) 
Effects of erythropoietin and pentoxifylline on the oxidant and antioxidant systems in the experimental short bowel syndrome. Cell Biochem. Funct., 21, 49-54.

19. Mandell, G.L. (1988) ARDS, neutrophils and pentoxifylline. Am. Rev. Respir. Dis., 138, 1103-1105.

20. Tesarik, J., Mendoza, C. and Carreras, A. (1992) Effects of phosphodiesterase inhibitors, caffeine and pentoxifylline, on spontaneous and stimulus-induced acrosome reactions inhuman sperm. Fertil. Steril., 58, 1185-1190.

21. Garbers, D.L., Lust, W.D., First, N.L. and Lardy H.A. (1971) Effect of phosphodiesterase inhibitors and cyclic nucleotides on sperm respiration and motility. Biochemistry, 10, 18251831.

22. Porter, J.M., Cutler, B.C., Lee, B.Y., Reich, T., Reichle, F.A., Scogin, J.T. and Strandness, DE. (1982) Pentoxifylline efficacy in the treatment of intermittent claudication, multicenter controlled double-blind trial with objective assessment of chronic occlusive arterial disease patients. Am. Heart J., 104, 66-72.

23. Oliva, A., Dotta, A. and Multigner, L. (2009) Pentoxifylline and antioxidants improve sperm quality in male patients with varicocele. Fertil. Steril., 91, 1536-1539.

24. Maxwell, D.T., Jacobson, J.D., King, A. and Chan, P.J. (2002) Effect of pentoxifylline on tumor suppressor and proto-oncogene apoptosis in sperm. J. Assist. Reprod. Genet., 19, 279283.

25. Terriou, P., Hans, E., Giorgetti, C., Spach, J.L., Salzmann, J., Urrutia, V. and Roulier, R. (2000) Pentoxifylline initiates motility in spontaneously immotile epididymal and testicular spermatozoa and allows normal fertilization, pregnancy, and birth after intracytoplasmic sperm injection. J. Assist. Reprod. Genet., 17, 194-199.

26. Faka, B., Api, M., Fiçicioğlu, C., Gürbüz, A. and Oral, O. (1994) Pentoxifylline in male-factor infertility, its therapeutic efficacy after oral administration. Acta Eur. Fertil., 25, 351353.

27. Noyan, T., Yalcinkaya, A.S., Sekeroglu, M.R., Dulger, H. and Balaharoglu, R. (2004) Antioxidant effects of pentoxifylline and melatonin in the alloxane-induced diabetic mice. Turk. $J$. Biochem., 29, 268-272.

28. Alizadeh, N., Abbasi, M., Abolhassani, F., Amidi, F., Mahmoudi, R., Hoshino, Y., Sato, E. and Ragerdikashani, I. (2010) Effects of aminoguanidine on infertile varicocelized rats: A functional and morphological study. Daru, 18, 51-56.

29. Nikseresht, M., Fallahzadeh, A.R., Toori, M.A. and Mahmoudi, R. (2015) Effects of pomegranate seed oil on the fertilization potency of rat's sperm. J. Clin. Diagn. Res., 9, FF01-4.

30. Ilbey, Y.O., Ozbek, E., Simsek, A., Otunctemur, A., Cekmen, M. and Somay, A. (2009) Potential chemoprotective effect of melatonin in cyclophosphamide- and cisplatin-induced testicular damage in rats. Fertil. Steril., 92, 1124-1132.

31. Nassar, A., Omara, H.M., Sary, A.E.K.H., Ahmed, E. and Ragab, S.M.M. (2012) Vitamin C, N, N-diphenyl-p-phenylenediamine and L-cysteine ameliorate the pathological and oxidative Stress-induced by cisplatin in the lidneys of male rats. J. Free Radic. Antioxid., 138, 112-121.

32. Ahmed, E.A., Omar, H.M., Abdelghaffar, S.K., Ragb, S.M. and Nasser, A.Y. (2011) The antioxidant activity of vitamin $\mathrm{C}$, DPPD and L-cysteine against Cisplatin-induced testicular oxidative damage in rats. Food Chem. Toxicol., 49, 11151121.

33. Ravi, R., Somani, S.M. and Rybak, L.P. (1995) Mechanisms of cisplatin ototoxicity: antioxidant system. Pharmacol. Toxicol., 76, 386-394.

34. Iwasaki, A. and Gagnon, C. (1992) Formation of reactive oxygen species in spermatozoa of infertile patients. Fertil. Steril., 57, 409-416.

35. Sanocka, D. and Kurpisz, M. (2004) Reactive oxygen species and sperm cells. Reprod. Biol. Endocrinol., 2, 12.

36. Sikka, S.C. (1996) Oxidative stress and role of antioxidant in normal and abnormal sperm function. Front. Biosci., 1, e78e86.

37. Turk, G., Atessahin, A., Sonmez, M., Ceribasi, A.O. and Yuce, A. (2008) Improvement of cisplatin-induced injuries to sperm quality, the oxidant-antioxidant system, and the histologic structure of the rat testis by ellagic acid. Fertil. Steril., 89, 1474-1481.

38. Atessahin, A., Karahan, I., Turk, G., Gur, S., Y1lmaz, S. and Ceribas1, A.O. (2006) Protective role of lycopene on cisplatininduced changes in sperm characteristics, testicular damage and oxidative stress in rats. Reprod. Toxicol., 21, 42-47.

39. Tremellen, K. (2008) Oxidative stress and male infertility-a clinical perspective. Hum. Reprod. Update, 14, 243-258.

40. Minaei, M.B., Barbarestani, M., Nekoonam, S., Abdolvahabi, M.A., Takzare, N., Asadi, M.H., Hedayatpour, A. and Amidi, F. (2012) Effect of Trolox addition to cryopreservation media on human sperm motility. Iran J. Reprod. Med., 10, 99-104.

41. Narayana, K., Al-Bader, M., Mousa, A. and Khan, K.M. (2012) Molecular effects of chemotherapeutic drugs and their modulation by antioxidants in the testis. Eur. J. Pharmacol., 674, 207-216.

42. Conklin, K.A. (2000) Dietary antioxidants during cancer chemotherapy: impact on chemotherapeutic effectiveness and development on side effects. Nutr. Cancer, 37, 1-18.

43. Pérez-Rojas, J.M., Cruz, C., García-López, P., SánchezGonzález, D.J., Martínez-Martínez, C.M., Ceballos, G., Espinosa, M., Meléndez-Zajgla, J. and Pedraza-Chaverri, J. (2009) Renoprotection by alpha-mangostin is related to the attenuation in renal oxidative/nitrosative stress induced by cisplatin nephrotoxicity. Free Radical. Res., 43, 1122-1132.

44. Sanchez, P.Y., Morales, B.R., García-Cuellar, C.M., Lopez, M.R., Calderon, O.M., Pedraza, C.J. and Chirino, Y.I. (2010) The alpha mangostin prevention on cisplatin-induced apoptotic death in LLC-PK1 cells is associated to an inhibition of ROS production and p53 induction. Chem. Biol. Interact., 188, 144-150.

45. Yousef, M.I., Saad, A.A. and El-Shennawy, L.K. (2009) Protective effect of grape seed proanthocyanidin extract against oxidative stress induced by cisplatin in rats. Food Chem. Toxicol., 47, 1176-1183.

46. Saad, A.A., Yousef, M.I. and El-Shennawy, L.K. (2009) Cisplatin induced damag in kidney genomic DNA and nephrotoxicity in male rats: the protective effect of grape seed proanthocyanidin extract. Food Chem. Toxicol., 47, 14991506.

47. Jariyawat, S., Kigpituck, P., Suksen, K., Chuncharunce, A., Chaovanalikit, A. and Piyachaturawat, P. (2009) Protection 
against cisplatin-induced nephrotoxicity in mice by Curcuma comosa Roxb, ethanol extract. J. Nat. Med., 63, 430-436.

48. Iraz, M., Ozerol, E., Gulec, M., Tasdemir, S., Idiz, N., Fadillioglu, E., Naziroglu, M. and Akyol, O. (2006) Protective effect of caffeic acid phenethyl ester (CAPE) administration on cisplatin-induced oxidative damage toliver in rat. Cell Biochem. Funct., 24, 357-361.
49. Choudhury, R.C. and Jagdale, M.B. (2002) Vitamin E protection from potentiation of the cytogenetic toxicity of cisplatin in Swiss mice. J. Chemother., 14, 397-405.

50. Narayana, K., Verghese, S. and Jacob, S.S. (2009) I-Ascorbic acid partially protects two cycles of cisplatin chemotherapyinduced testis damage and oligo-astheno-teratospermia in a mouse model. Exp. Toxicol. Pathol., 61, 553-563. 